In severe forms of the disease, with considerable lateral displacement or subluxation of the femoral head, infraction of part or all of the uncovered area of the epiphysis, widening of the epiphysial nucleus, or a slow rate of healing, longcontinued conservative treatment is needed or, as has recently been suggested, surgical intervention by upper femoral ${ }^{67}$ or innominate osteotomy. ${ }^{8}$ It is still too early to assess the true results of such treatment. Techniques such as drilling of the growth plates, fenestration, and bone grafting have all been popular at one time and have all been rejected ultimately. Femoral or innominate osteotomy, which aims to improve the containment of the femoral head, appears to have a logical basis for its performance, but only the longterm follow-up of sufficient numbers of severely affected hips will show whether these procedures will fulfil the high hopes of their authors.

1 Catterall, A., fournal of Bone and foint Surgery, 1971, 53-B, 37.

Zahir, A., and Freeman, M. A. R., fournal of Bone and foint Surgery, 1972, 54-A, 125.

3 Kemp, H. B. S., Annals of the Royal College of Surgeons of England, 1973, 52,18 .

4e Valderrama, J. A. F., fournal of Bone and foint Surgery, 1963, 45-B, 462 .

Jacobs, B. W., Fournal of the American Medical Association, 1960, 172, 527 - Axer, A., fournal of Bone and foint Surgery, 1965, 47-B, 489.

Somerville, E. W. Fournal of Bone and foint Surgery, 1971, 53-B, 639.

8 Canale, S. T., D'Änca, A. F., Cotler, J. M., and Snedden, H. E., Fournal of Bone and foint Surgery, 1972, 54-A, 25.

\section{Renal Carbuncle}

Debilitation is a classical precursor of renal carbuncle, and so is diabetes. Most reported cases were in young adults before the days of penicillin. But in recent years we have grown used to the idea that the disease is extinct-a condition only to be seen at surgical examination and then in pots well bleached by age. There are signs that this happy interlude is over. In 1968 O. E. Cobb' ${ }^{1}$ reported four cases of the condition to remind surgeons that it still could occur. Now it appears that debilitated drug addicts, who give themselves unclean intravenous injections through dirty needles, are specially prone to this disease. ${ }^{2}$

The organisms reach the kidney through the blood stream. Classically they are staphylococci derived from distant boils, septic fingers, chest infections, osteomyelitis, and infected abrasions and insect bites. Other organisms can cause an identical lesion. J. G. Rabinowitz and colleagues report two men who developed a carbuncle from coliform organisms probably originating in prostatitis. ${ }^{2}$ In several series ureteric obstruction seems to play a part in the origin of the carbuncle, though the pattern of inflammation in the kidney is different from usual. Unlike the common suppurative pyelonephritis, in which it spreads in a distinct wedge outwards from calices, in carbuncle the blood-borne organism forms a cortical abscess, and the infection spreads out into adjacent parenchyma to form a more or less confluent collection of abscesses without any well-defined wall. In contrast to pyelonephritis the suppurative lesion of the carbuncle is not in communication with the renal collecting system. When it spreads it does so centrifugally and forms a perinephric abscess.

Patients present with the general features of a severe infection with fever and rigors, a raised erythrocyte sedimentation rate, and a polymorphonuclear leucocytosis. They have no urinary symptoms as a rule, and the urine is free from pus or organisms, but pain in the loin may suggest trouble in the kidney. A plain radiograph shows the spine curved away from the side of the lesion, the psoas border is blurred, and the renal shadow is obscured by soft tissue swelling. The excretion urogram may show delayed or even absent excretion, but it may disclose a soft tissue mass displacing and compressing adjacent calices.

These features may suggest renal carcinoma, especially in a patient given antibiotics to overcome acute inflammation. An arteriogram may help to make the diagnosis, especially in the early stages, for no tumour circulation will be seen and the renal vessels will be shown displaced by the soft tissue lump. In more chronic cases, and later on in the course of the disease, angiography may cause confusion by showing inflammatory vessels that may be mistaken for those of a neoplasm. . $^{3-5}$

The best treatment is by antibiotics, though coexisting ureteric obstruction may need to be dealt with specifically. The antibiotics must be kept up until all the clinical and radiographic features have disappeared, when the kidney may be expected to return to normal.

1 Cobb, O. E., British fournal of Urology, 1966, 38, 262.

2 Rabinowitz, J. G., Kinkhabwala, M. N., Robinson, T., Spyropoulos, E., and Becker, J. A., American fournal of Roentgenology, 1972, 116, 740. ${ }^{3}$ Caplan, L. H., Siegelman, S. S., and Bosniak, M. A., Radiology, 1967, 88, 14.

4 Caro, G., Meisell, R., and Held, B., Radiology, 1969, 92, 1262.

5 Himmelfarb, E. H., Rabinowitz, J. G., Kinkhabwala, M. N., and Becker, J. A., Fournal of Urology, 1972, 108, 846.

\section{Nasal Polyps}

The respiratory mucous membrane lines nearly the whole of the nasal cavities and all the nasal accessory sinuses. Its function as an air conditioner almost constitutes it an organ in its own right, and to fulfil this function it produces an enormous amount of viscid secretion. This secretion is moved by ciliary action from the interior of the sinuses into the nasal cavities and thence to the nasopharynx, where it accumulates until an act of swallowing is evoked. The mucus is then passed into the alimentary canal and not, as is commonly believed, into the respiratory tract.

The particles of atmospheric organic and inorganic matter which adhere to the mucus in passing through the nose are digested and destroyed in the stomach and intestines. The mucus also helps to adjust the temperature and humidity of the inhaled air. The constant production of mucus is mediated by a blood-supply capable of rapid and considerable variation. In the corium of the mucosa is a vast and largely dormant network of capillaries, arterioles, and venules finely adjusted to dilate or contract in a natural response to atmospheric conditions, but also to other stimuli, psychogenic, infective, and allergic. The respiratory mucosa is perhaps the commonest site of hypersensitivity reactions, ranging from the almost specific disease of hay fever to the even more common miseries of perennial bouts of sneezing and watery rhinorrhoea.

The common factor is an exudative process as the walls of the numerous peripheral blood vessels become permeable and fluid passes from the blood stream into the tissues. Sometimes a generalized oedema occurs, resulting in a wet, pale, and thick mucosa pouring fluid from its surface in a watery flow. At other times, for unknown reasons, the fluid 